\title{
Role of fashion as a form of therapy among women with disabilities in South African
}

\author{
Vivence Kalitanyi \\ Department of Business Management \\ University of Johannesburg, South Africa
}

\section{Keywords}

body image, disability, fashion, women with disability, Johannesburg, South Africa.

\begin{abstract}
Purpose: Previous studies have highlighted the important role, fashion can play on one's cognition and behaviour and how one's body is impacted, especially people with disabilities. Due to the inconclusive results on the topic, we decided to undertake an empirical study in South Africa to determine how fashion can be used to help women with disabilities to deal with issues of body image, low esteem and negative mindset.

Literature review: The study reviewed the literature on body image and disability, body image and fashion as well as on fashion therapy and body image.

Methodology: The study adopted a qualitative research design while interviews were used as means of primary data collection. Data analysis was done by means of coding the participants' responses before conclusions were drawn about the participants' views. Findings: Findings reveal that fashion can help women with disabilities to deal with the issues related to low self-esteem and body image.

Implications: The study ends with recommendations to include other segments of the disabled community in the study, as well as to expand the study in the other parts of the country. The study adds a tremendous knowledge of how to better treat people with disability.
\end{abstract}

Corresponding author: Vivence Kalitanyi

Email addresses for the corresponding author:vkalitanyi@uj.ac.za

The first submission received: $22^{\text {nd }}$ July 2021

Revised submission received: $10^{\text {th }}$ September 2021

Accepted: $18^{\text {th }}$ October 2021

\section{Introduction}

Many women with disabilities are experiencing body image and low self-esteem issues in their living environments. This has led to the development of studies on how disabilities affect body image and how women with disabilities, especially those between the age of 20-35 use fashion as a form of therapy. In South Africa, "disabilities" is an umbrella term used to define impairments, activity restrictions or both, that individuals may face over a long-term or recurring period (South African Employment Equity Act 55 of 1998). In support of this definition of the Act, the South African Human Rights Commission (2017) stipulates those impairments may be of a physical and/or mental nature, where a physical impairment relates to "a partial or total loss of a body function or part of the body" while a mental impairment is a condition which impacts one's "thought, processes, judgment or emotions".

Consistent to the above definitions and in line with the current study, Tiwari and Kumar (2015) described the concept of body image as relates to the "perceptions" individuals have of their bodies, often relating to physical features, impacted by society one's body image has the ability to affect their mental health and "well-being".

Venkatasamy and Saravanan (2015) postulate that not enough research has been conducted to investigate how fashion can be used as a therapy, specifically to the people with disabilities. Generally, fashion is used for artistic, cultural, communication, political and various other reasons, and despite its significant amount of potential it has to help women with disabilities, it is rarely used for the betterment of the society.

However, as stated by Son, Kim, Lee and Lee (2015), this distant attitude towards the therapeutic role of fashion has started to shift its position in society as many have noticed the positive impact that fashion now has on people's "attitude, behaviours and emotions". Son et al., (2015) go further and explain that 
fashion is also used as a form of "grooming" to better physical appearance acts therapeutically, as it improves body image; therefore, impacting one's mental health in a positive way.

This study aims to make a contribution in the way people understands disability among women, and how fashion can be used to deal with issues that affect those women with disabilities in South African context.

\section{Literature review}

In situations where individuals have visible impairments, one's body image is often negatively impacted as they are often discriminated by society and seen as imperfect for not looking like a nondisabled person, therefore, causing individuals with disabilities to feel embarrassment and self-loathing, as their emotions towards themselves are moulded by societies opinions about them (Taleporos \& McCabe, 2002). Regardless of this old literature, the core of their work about human behaviour, body image and disabilities still remain relevant as it is still on par with recent research stating that self-image is directly related to one's "mental health" (Shpigelman \& HaGani, 2019:2-3).

Based on the positive impact that fashion has on individuals, it is safe to say that the discipline of fashion could potentially be used to make positive changes in one's body image, improving the state of mind individuals with disabilities have about themselves. It is also possible that the use of Fashion Therapy (FT) could not only have an impact on women with disabilities but also on society and its way of viewing people with disabilities.

\section{Body Image and Disability}

Grogan (2006); Cash and Smolak (2011); and Bailey, Gammage, van Ingen and Sarcone (2017) contend that "body image is a construct with cognitive, behaviour, and emotional elements as they relate to physical appearance". This suggests that body image is a result of the way one thinks, feels and acts, in connection to the way that individual looks.

Taleporos and McCabe (2002); Shakespear, Gillespie-Sells, and Davies (1996) speak about how people with physical disabilities are immediately shamed by society due to their conditions. This results in these individuals to look down on themselves and poor self-esteem. Based on the poor body image formed by the cynical impact society has on women with disabilities, their "cognition, behaviour, and emotions" suffer. These women with disabilities are trained to see themselves the way society perceives them, linking back to Sarcone (2017).

Furthermore, Taleporos and McCabe (2002) and Mayers (1978), postulate that women with disability need to be trained to look at themselves in a full-length mirror and working toward seeing themselves as attractive and not as the ugly creature that some societies had pushed them to believe they were. A woman with a disability can uses fashion to feel beautiful and confident, gradually building on her body image and self-esteem. By using fashion for these reasons, she is training herself to believe that she is beautiful, thus relating to FT.

\section{Body Image and Fashion}

Dimka, Kabel and McBee-Black (2017) speak about the psychology of clothing and how fashion has a positive impact on one's mental health, self-esteem and therefore, one's body image. Dimka, Kabel and McBee-Black (2017) and Turner (1993), report that the embodiment of clothing could act as a "social skin", as clothing impacts one's body image and mental health. The "social skin" implying that fashion can be used to better one's body image. Dimka, Kabel and McBee-Black (2017) also express that the feel of specific clothing or accessories can evoke memories in people with mental disabilities. By evoking memories in people, the garment or accessory is likely to act as comfort for individuals, allowing them to develop confidence and an improved body image. Sarcone (2017) cites Tomas and Marron (2016) and McDermott, Mullen, Moloney, Keegan, Byrne, Doherty, Cullen, Malone, and Mulcahy's (2015) work to explain that fashion is used as a "canvas" where individuals can express themselves, and can; therefore, relate to the "social skin", where individuals can use clothing to express themselves in a confident manner.

Additionally, Son et al., (2015) posit that fashion influences one's "attitudes, behaviours, and emotions", while Sarcone (2017) explained that one's body image is influenced by one's "attitudes, 
behaviours, and emotions". Both authors, together with Dimka, Kabel and McBee-Black (2017) substantiate one another in their works, as they all link and correspond with one another.

In a different view, Mair (2018) expresses that the ideals of beauty change with time and that many "people want to match the ideals of their time and culture". The incurred poor body image is because their disabilities differentiate them from what society deems normal and attractive. Irrespective of whether individuals are able or disabled, the urge to fit in with current times relates to one having a sense of security. Therefore, a better self-esteem and body image is related to fashion conformity, as fashion acts as an outward appearance and "social skin", which is substantiated by Turner (1993), cited in the work of Dimka, Kabel \& McBee-Black (2017:19), and Masuch \& Hefferon (2014:235).

\section{Fashion Therapy and Body Image}

Son et al., (2015:114-115) cites Horn and Gurel (1981) and Thompson (1962), expressing that FT is a form of "psychotherapy". Therefore, FT could potentially enable individuals with disabilities to improve their body image and self-esteem through the use of fashion, as fashion has the ability to change the appearance of people. FT, as a form of "psychotherapy" could be successful if used by women with disabilities to improve their body image. Literature substantiates that FT can be used to enhance one's body image, as fashion influences how one acts and thinks (Adam \& Galinsky, 2012:918-919). The influence on one's mind and behaviour impact their body image and self-perception (Dimka, Kabel \& McBee-Black, 2017:18-20).

Revisiting what Dimka, Kabel and McBee-Black (2017:18-20) expressed in Body Image and Fashion, clothing that is of significance and comfort to someone with a disability could improve their selfconfidence and mental health. These improvements are due to the clothing acting as a comfort-zone for them. The clothing, therefore, allows the individual to feel confident and happy in their skin (Dimka, Kabel \& McBee-Black, 2017:18-20). Turner (1993) cited by Dimka, Kabel and McBee-Black (2017:19), states that fashion as a "social skin" could impact one's body image and psychological state. This impact confirms that fashion can act as a form of therapy for women with a disability.

Dimka, Kabel and McBee-Black (2017:18-20) reports further that one can be reminded of memories by the touch and feel of garments and accessories. If women with disabilities use fashion that has happy and positive memories attached to it, as the memories would then influence the behaviour and emotions of the individual, potentially acting as therapy Sarcone (2017), and this ties in with what the aim of the study is. The work of Sarcone (2017) can be useful in the development of this study as it touches on the psychology of body image; as well as, body image and fashion, allowing for a deeper understanding that is valuable to the study.

Moody, Langdon and Karam (2018) cite Moody et al., $(2009,2010)$ and Kang, Johnson and Kim (2015), substantiating the theory that one's behaviour, emotions and cognition are potentially impacted by fashion, overall having the ability to shape the "well-being" of the user. Again, this literature works to prove the theory and objectives being researched in this study, as FT can be used to better one's emotions, cognition and actions, which in turn has a positive impact on one's body image.

\section{Research methodology}

The study being conducted is of a qualitative nature, since the purpose of this study is to gain rich, meaningful information which helps develop understanding to improve and better individuals and society. Being psychology-based research, the methodological choice used in this study is qualitative, as the study uses qualitative approach to investigate and find understanding around, fashion, body image, therapy and people with disabilities (Creswell, 2014:4).

\section{The research strategy}

Due to the nature of this study being qualitative, implying that the study is looking for accurate, unbiased and meaningful data, verifies the choice of using a survey as the research strategy. By means of interviews, the study used the narrative research strategy where participants re-counted their stories about their experiences of living with disabilities. 


\section{Population}

The population of this study are women with disabilities in Johannesburg, between the ages of 20-35. This population is unknown and difficult to quantify without official South African statistics.

\section{Sampling}

The sample group chosen to represent the population for this study is based in the workplace of Progression, where all learners have either a physical or mental disability. The sample technique used in this study is the convenience technique, due to the sample group being based in the workplace, collecting data only from those willing to participate (Alvi, 2016). The convenience technique is appropriate for this study as the research is based on women with disabilities, which is majority of Progression's learners. The sample group is women aged 20-35 years and are all residing or working in Johannesburg. All participants have been diagnosed with a long-term disability by a medical practitioner, of which, their medical notes confirming their disabilities are verified and checked by the employers. The sample size chosen to represent the group of women with disabilities is approximately 30 respondents, as the sample group needs to be large enough to provide an accurate, reliable and relevant representation of the population it is representing.

\section{Data collection and analysis}

In this study, data is collected by means of interviews. Once the data has been collected, the data was analysed with colour coding, according to the question, and the answers to each question were coded by a key. Lastly, each question was coded by a shape according to which category the questions and answers fall. For instance, each category such as "user-psychology", "body image and disability", "fashion and therapy", and so forth would each have their colour, as data analysed can be colour coordinated according to the categories. Once coded, the categorised data were analysed, and the coding were reviewed, funnelling down the data and ensuring that only what is relevant is being used. The reviewing and funnelling of data occurred at least three times to ensure a thorough analysis of data. Notes were made during the coding process, probably on sticky notes as reminders of meanings, and concepts that are being brought up or carried through the research. Once the coding process was complete, the data was interpreted, and any qualitative findings were displayed visually to enable easy reading and analysis for the reader. Ways in which data were visually represented are by tables, diagrams and charts.

\section{Questionnaire Development}

There was no existing questionnaire to fulfil the purpose of this study. Therefore, the interview schedule was a self-designed. The point of departure was the identification of gaps in the literature, from which the questions were formulated.

All questions were developed to answer each research question; as well as, to fulfil the research objective and purpose. In this process, the questions were carefully worded and phrased to prevent any unethical issues, leading questions or misunderstanding. All questions were drafted and developed while writing out the literature review and research objectives. The questions were written as drafts, from which they were continuously revised and edited until they were at satisfactory level.

Lastly, the questions are re-arranged to create a logical and smooth flow. The questionnaire is deemed valid as it has been reviewed and approved by experts in the field. These experts had assisted in the process of revising and modifying questions, ensuring that the questionnaire aids in achieving all objectives of the study. Furthermore, the review process ensured that all questions were in line with the literature review and objectives being studied.

\section{Findings/results and their discussions Participant's identities}

This study intends to identify and explore, through the views of women with disabilities, if fashion can be used as a form of therapy to improve the body image of women with disabilities. The participants in this study represent all types of disability, as the study does not focus on the distinction between physical and mental disabilities. In this study, 34 participants between the 20-35 we surveyed, where 50\% of participants were in the age range of $31-35,35 \%$ aged between $26-30$, and only $15 \%$ of participants were aged 20-25 (as seen below). 
All participants either work or reside in the Johannesburg region. This geographical data is evident in question 2; as well as, by the survey being conducted in the workplace (Progression). All participants are learners at Progression and therefore is evident that they have a professionally diagnosed disability (as a medical certificate is required for a learnership position at Progression).

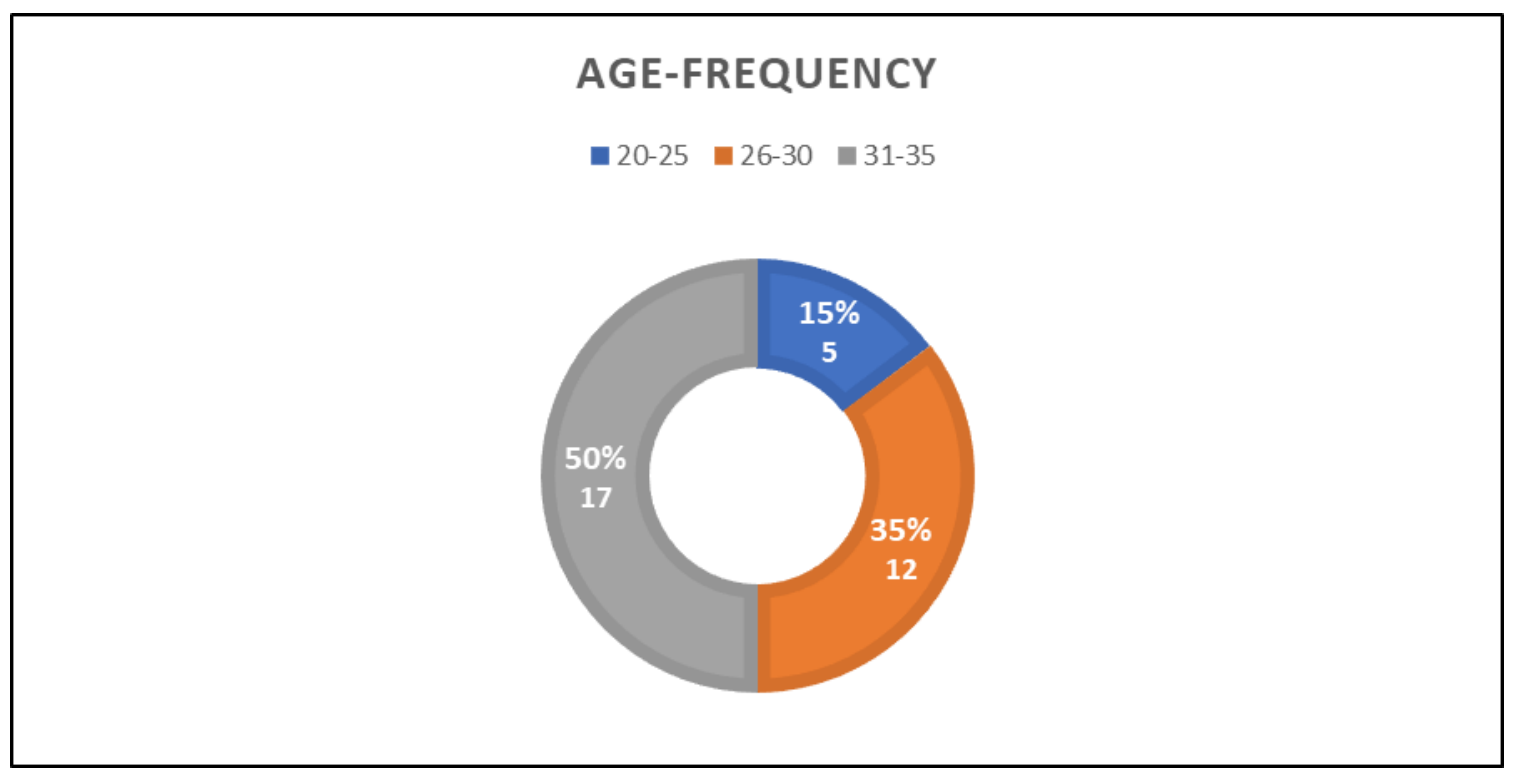

This chart shows the age group statistics of participants and the frequency of each age group.

\section{The impact of disability on body image}

Majority of the participants believe that their body image is not affected by their disability, this could be a result of the fact that many individuals have dealt with and accepted their body image; however, it seems that many participants did not understand the term body image, despite being provided with the definition. This misunderstanding seems apparent as many participants speak about the actual appearance of their body, rather than the way they view and feel about their body and appearance. The potential misunderstanding could cause participants to answer out of context, therefore, creating an error in the data. Additionally, many participants stated that their body image is not affected by their disability as their disability is not physical and visible; therefore, they are not judged by society. This finding relates to Taleporos and McCabe (2002) who state that those with more significantly visible disabilities are prone to a substantially poor body image due to the barriers formed against them in comparison to those with milder or non-visible disabilities. Lastly, many participants stated that they deal with their body image by looking after their bodies and health, which could make them feel better and, therefore, improve their confidence and body image. Individuals that have and are still dealing with their body images relates to Taleporos and McCabe (2002) citing Mayers (1978), who speaks about training oneself to feel beautiful and confident

On the contrary, many participants expressed that their body image does affect their self-esteem and body image, mostly due to many of these participants having significantly visible disabilities (Mayers, 1978 cited in Taleporos and McCabe, 2002:972-973). Additionally, many explained that over time, they had acquired their disability, making them feel self-conscious. Furthermore, individuals have experienced physical changes in their appearance over time, which can be the result of the inability of some participants to move enough or due to the physical changes caused by their disability. As reported by Grogan (2006); Cash \& Smolak (2011); Bailey, Gammage, van Ingen and Ditor (2016) cited in Sarcone (2017), such changes in their appearance due to their disability can cause a significant drop in an individual's body image as "body image is a construct with cognitive, behavioural, and emotional elects as they relate to physical appearance". 
Many participants also expressed that they feel as though they cannot wear certain clothes due to their disability. These small yet significant restrictions on individuals cause them to have low self-esteem and body image, as their disabilities already cause differentiation between them and what society deems 'normal'. Now the differentiation seems more apparent to these individuals due to the struggle of finding fashionable and accommodating clothing (Mair, 2018; Shakespear, Gillespie-Sells, \& Davies, 1996:3 cited in Taleporos \& McCabe, 2002:971-974).

\section{Influences of society}

Based on data collected, the majority of the participants is or has been affected by the way society views them, proving that one's body image and self-esteem can be improved over time. In the same way, Dimka, Kabel \& McBee-Black (2017:20) reported that many participants feel that society makes them feel as though they are not good enough as "barriers" are formed against individuals with disabilities; therefore, negatively impacting their body image and self-esteem. Some participants were laughed at and made to feel "stupid" as they are "discredited" by society due to their disability (Dimka, Kabel \& McBeeBlack, 2017:18-20; and Taleporos \& McCabe's, 2002:972-973). Participants expressed that they are perceived as strange and incapable by society, causing them to lose confidence and self-esteem.

This attitude towards people with disability is, in fact, a violation of Chapter 2, Section 9 (3) and (4) of the South African Constitution which prohibits any individual to discriminate against anybody including people with disabilities.

Similarly, many participants expressed that they battled to adjust to their disability and the way society treats them; however, with much work, they have reached the point of self-acceptance, making it easier for them to cope with their disability and society. This finding proves that there is potential in improving one's body image. These individuals make a point of feeling good as they understand that society has a minimal understanding of disability, helping them attain self-love and an improved body image. For participants that are in the process of reaching this point of self-love and an improved body image, fashion is a good starting point, as one can use fashion as a "social skin" to feel good and confident (Turner, 1993 cited in Dimka, Kabel \& McBee-Black, 2017:19).

On the contrary, many participants stated that the way society views them have no impact on the way they feel and view themselves. This lack of impact could be due to these participants having a mental or minor physical disability, therefore meaning that it is probable that participants do not receive adverse reactions from society, as society treats them like an abled person (Taleporos \& McCabe, 2002:972-973). Additionally, it is possible that participant who was born with their disability have accepted themselves and their disability and deemed themselves beautiful; therefore, not being moved by what society thinks of them.

\section{The impact of fashion on body image}

Majority of the participants in this study believes that fashion and body image are related. This finding is evident as participants feel that when they dress up, they feel good; therefore, impacting their confidence and body image. This finding verifies Dimka, Kabel and McBee-Black (2017:18-20) who states that fashion has the potential to have a positive impact on one's mental health, self-esteem and body image. Individuals who feel confident when they dress up substantiate the work of Son et al., (2015:114115) who state that fashion influences one's "attitudes, behaviours, and emotions", possibly meaning that the embodiment of fashion has the potential to change the way one perceives oneself.

Furthermore, more than $90 \%$ of the participants said that their clothing choice has the ability to improve their self-esteem and body image. Most participants stated that choosing to wear clothing that makes them feel good automatically boosts their confidence. This confidence boost uplifts their selfesteem and body image, creating a space for one to practice and develop self-love. The created space for the development of self-love directly relates to Mayer's (1978) cited by Taleporos and McCabe (2002:972973) mirror concept, where a woman needs to train herself to feel beautiful when she looks in a full-length mirror. Fashion can be a starting point for the practice of this concept, as a woman with a disability can view herself in a full-length mirror while wearing clothing that makes her feel attractive and confident.

Additionally, the majority of participants expressed that society treats them based on their fashion, impacting their body image and confidence. These participants expressed that fashion is a reflection of a 
person and their character. As women with disabilities, clothing act as a communicator between them and society; therefore, when an individual with a disability dress up, they tend to be treated better by society, as their clothing portrays a pleasant image of them. Using fashion as a communicator between an individual with a disability and society could relate to the "social skin" theory by Turner (1993) cited by Dimka, Kabel and McBee-Black (2017:19) where individuals use fashion as a "social skin" to portray an image of themselves to society. This image impacts the way society treats individuals with disabilities.

Furthermore, participants express that being noticed and treated well by society improve their body image and boost their confidence, making them feel good about themselves, linking back to the "social skin" theory. Lastly, participants feel that when they are dressed up, society tends to focus more on their clothing rather than their disability, again relating to the "social skin", where this time the "social skin" can be interpreted as a cover or façade, allowing individuals to show society what they are most comfortable showing.

Moreover, participants feel that clothing made especially for individuals with disabilities could be beneficial for their self-esteem due to many reasons. One reason being, often many physically disabled individuals, grow frustrated as they cannot find clothing that accommodates their disability while being fashionable, therefore discouraging them and lowering their self-esteem. Participants believe that customised clothing for physically disabled individuals provides a variety and easy access to fashionable yet accommodating clothing; therefore, making women feel good about themselves as they do not have to struggle to find clothing.

This finding relates to the work of Mair (2018); Shakespear, Gillespie-Sells, and Davies (1996:3) cited by Taleporos and McCabe's (2002:971-974) where individuals with disabilities have poor body images due to their disabilities differentiating them from the norms of society. Therefore, due to this differentiation, these individuals have a strong urge to conform to the current fashion, creating an outward appearance that will help them fit in and be accepted by society. By eliminating the struggle and frustration of finding suitable clothing, women will begin to feel more comfortable as the clothing is accommodating their and disability, while acting as a comfort-zone, allowing them to feel confident and happy in their own skin (Dimka, Kabel \& McBee-Black, 2017:18-20). As well as, confident as they will not have the struggle of finding fashionable clothing and will be able to fit in with the current zeitgeist (Mair, 2018). The comfort and confidence experienced by the individuals will result in an improvement in their body image and self-esteem as they will deem themselves "attractive" and "normal".

\section{Fashion therapy}

With the majority of the participants believing that their choice in fashion can improve their selfesteem, it is evident that fashion can be used as a form of therapy; therefore, FT. FT is used as a form of "psychotherapy", as one's behaviour, cognitive state and emotions are impacted by fashion (Horn and Gurel, 1981 \& Thompson, 1962 cited in Son et al., 2015:114-115). Participants expressed that when they dress up, they felt confident, therefore, improving their self-esteem and body image. Similarly, many participants said they had used fashion to improve their self-esteem and body image. This use of fashion, where one deliberately uses fashion to feel confident and beautiful is a form of therapy, as fashion influences the way one thinks, act and feels (Adam \& Galinsky, 2012: 918-919). This influence on the way one feels thinks and acts impacts their confidence, body image and self-esteem (Dimka, Kabel \& McBeeBlack, 2017:18-20).

Furthermore, participants believe that FT is an excellent place to start accepting their disability, as FT would help them use fashion and clothing to feel beautiful and value themselves more. By feeling beautiful and valuing oneself, the individual begins to gain confidence; as a result, improving their body image and self-esteem. Additionally, participants believe that FT is an excellent way to get participants to step out of their comfort zone and try new styles; thereby helping them to find what they are most comfortable in and what makes them feel most beautiful- in turn, influencing their body image and confidence.

Similarly, participants believe that the way society views them impacts their body image, as society treats them differently based on how they are perceived. Participants believe that what they wear will impact the way society views them; therefore, impacting their confidence and body image. This finding relates to the theory that individuals use fashion to create perceptions of themselves to society. This use of 
fashion uses clothing as a "social skin". The "social skin" creates an image or façade of one's actual self, influencing the way society views them (Turner, 1993 cited in Dimka, Kabel \& McBee-Black, 2017:19).

The "social skin" also acts as a communicator of between the individual with a disability and society, where the individual communicated and shows society only what they want to be seen (Tomas \& Marron, 2016; and McDermott, Mullen, Moloney, Keegan, Byrne, Doherty, Cullen, Malone, \& Mulcahy's, 2015 cited in Sarcone, 2017). Fashion as a "social skin" acts as a communicator; therefore, when an individual with a disability dresses up, society tends to treat them with more value and respect. As society begins to value these individuals, they start to feel accepted by society which improves their confidence. This confidence boost influences their body image and self-esteem.

To verify the theory in study, majority of the participants have used fashion to improve their selfesteem and body image. Many participants express that dressing up helped them feel "confident", "brave", "beautiful, "alive", "comfortable", and "attractive", which as a result, impacted their body image and self-esteem. Many also expressed that the way society treated them when they dressed up assisted them with their self-perception and confidence; therefore, substantiating the data discussed above. Additionally, many explained that when they feel down and unconfident, they often dress up or shop for new clothes. This way of dealing with confidence helped participants improve the way they feel about themselves; therefore, impacting their confidence, self-value and body image. Lastly, a few participants have not used fashion to improve their body image and self-esteem; however, some of these participants expressed that they have limited knowledge of fashion but finds the theory interesting and believes that it has the potential to work.

\section{Summary, recommendations and directions for future research}

The main objective of this study was to investigate if FT is a viable method to help improve body image amongst women with disabilities. This study aimed to investigate if fashion has a positive impact on women with disabilities; as well as, to explore the link between fashion as a form of therapy for women with disabilities. In this study, literature pertaining to disability and society, disability and body image, disability and fashion, and fashion and body image were reviewed.

From a theoretical point of view, the findings verified the reviewed literature on the effects of disability and society on body image, and the potential use of fashion as a form of therapy.

As a result of the findings, it was found that societies views of them impact individuals with disabilities. Therefore, fashion as a "social skin" has the potential impact an individual's body image and confidence, as it enabled individuals to cover up and show society only what they are comfortable with showing. Additionally, it was found that individuals with disabilities are treated differently due to their disabilities; however, it was discovered that society reacts to how an individual dress, where they tend to focus more on the clothing than on the disability; as a result, impacting the way they treat and view individuals with disabilities. Furthermore, data showed that participants have been practising FT on themselves, meaning that there is an excellent potential for the professional use of FT amongst women with disabilities.

Lastly, although the sample group of the study is not an accurate representation of the population, the researcher is confident that the aim and objectives of the study have been achieved.

\section{Recommendations and implications}

Given the information contained in the body of the literature on this topic, as well as the findings of the current study, the study formulates the following recommendations:

A proper understanding of the factors that affect the body image of individuals with disabilities is required by all members of the society.

A deeper exploration of the design aspects of customised clothing for individuals with physical disabilities.

The establishment of learnership programmes to promote the role of fashion as means of therapy among people with disabilities without any gender, race or age discrimination.

Given the context of the study, it is believed that the study will have a huge impact on the future orientation of fashion designers who focus or get orders from individual with disability. Furthermore, the 
findings of the current study will raise the level of awareness among the community that disable people deserve a better treatment and respect so that they can live in dignity.

\section{Limitations and directions for future research}

The current study only focused on women with disabilities and in a specific section of the country Johannesburg. Future research to include men and if possible, covers a broader area of the country.

Secondly, the future studies on the topic should investigate the methods and procedures of how fashion can be used as a form of therapy for individuals with disabilities.

And finally, future research should focus on how fashion can help women with disabilities to overcome the poor body image by means of differentiating between disabilities.

\section{References}

Adam, H., and Galinsky, A.D. (2012). Enclothed Cognition. Journal of Experimental Social Psychology, 48:918-919.

Alvi, M.H. (2016). A Manual for selecting sampling techniques in research. Munich Personal RePEc Archive. University of Karchi, Iqra University.

Bailey, KA., Gammage, KL., van Ingen, C., and Ditor, DS. (2016). Managing the stigma: Exploring body image experiences and self-presentation among people with spinal cord injury. Health Psychology Open, 3.

Cash, T.F., and Smolak, L. (2011). Body Image: A handbook of science, practice, and prevention. New York, NY: Guilford Press.

Creswell, J. W. (2014). Research Design: Qualitative, Quantitative, and Mixed Methods Approach. Thousand Oaks, CA: Sage.

Dimka, J., Kabel, A., and McBee-Black, K. (2017). Disability, Participation and Apparel throughout the Life Course. Anthropology \& Aging, 38(1), 18-20.

Grogan, S. (2006). Body Image and Health: Contemporary Perspectives. Journal of Health Psychology, 11:523-530.

Horn, M. J., and Gurel, L. M. (1981). The second skin. Boston: Houghton Mifflin.

Kang J-Y, M., Johnson, K.K.P., and Kim, J. (2015). Clothing functions and use of clothing to alter mood clothing functions and use of clothing to alter mood. Int J Fashion Des Technol Educ, 6(1):43-53.

Mair, C. (2018). The Psychology of Fashion. New York, NY: Routledge.

Masuch, C-S., and Hefferon, K. (2014). Understanding the links between positive psychology and fashion: A grounded theory analysis. International Journal of Fashion Studies.1(2): 235. Available from: https://www.researchgate.net/publication/267816511_Understanding_the_links_between_positive_ psychology_and_fashion_A_grounded_theory_analysis [Accessed: 18 February 2021].

Mayers, K. S. (1978). Sexual and social concerns of the disabled: A group counselling approach. Sexuality and Disability, 1(2): 100-111.

McDermott, E., Mullen, G., Moloney, J., Keegan, D., Byrne, K., Doherty, GA., Cullen, G., Malone, K., and Mulcahy, HE. (2015). Body image dissatisfaction: clinical features, and psychosocial disability in inflammatory bowel disease. Inflammatory bowel diseases, 21:353.

Moody, W., Langdon, P. M., and Karam, M. (2018). “Enhancing the Fashion and Textile Design Process and Wearer Experiences." In: Breaking Down Barriers Usability, Accessibility and Inclusive Design. London and Cambridge: Springer, 52.

Moody, W., Kinderman, P., Sinha, P., and You, K-S. (2009). Identifying the causal relationships of appearance management through an analysis of one's own clothing and wearing experiences over a 10-day period. J Korean Soc Clothing Text, 33(6):841-852.

Moody, W., Kinderman, P., and Sinha, P. (2010). An exploratory study: relationships between trying on clothing, mood, emotion, personality and clothing preference. J Fashion Mark Manage, 14(1):161-179.

Sarcone, K. (2017). Marginalized Consumers Exploring Disability, Body Image, and Clothing Consumption. Degree of Master of Public Health: Brown University School of Public Health.

Shakespeare, T., Gillespies-Sells, K., and Davies, D. (1996). The sexual politics of disability: Untold desires. London: Cassell, 3. 
Shpigelman, C-N., and HaGani, N. (2019). The Impact of Disability Type and Visibility on Self-concept and Body Image: Implications for Mental Health Nursing. Journal of Psychiatric and Mental Health Nursing. [Online] 26(3-4). 2-3. Available from:

https://onlinelibrary.wiley.com/doi/abs/10.1111/jpm.12513 [Accessed: 3 February 2021].

Son, H., Kim, S., Lee, J., and Lee, S. (2015). Rethinking Fashion Therapy: Theoretical and Practical Foundations for Value Creations in Clothing and Textiles Discipline. International Textile and Apparel Association (ITAA) Annual Conference

Proceedings. 72:114.

South Africa. (2002). EMPLOYMENT EQUITY ACT 55 OF 1998. Pretoria: Government Printer, sec 5.1. [Online] Available from: https://gestaltconsult.com/wp-content/uploads/2017/02/EmploymentEquity-Act-People-with-Disabilities.pdf [Accessed: 30 January 2021].

South Africa. (2017). South African Human Rights Commission. Pretoria: Government Printer, sec 1:13. [Online] Available from:

https:// www.sahrc.org.za/home/21/files/20170524\%20SAHRC\%20Disability\%20Monitoring\%20Frame work\%20and\%20guidelines\%20Draft\%205.pdf [Accessed: 30 January 2021].

Taleporos, G., and McCabe, M. P. (2002). Body image and physical disability- personal perspectives. Social Science $\mathcal{E}$ Medicine, 54, 971-974.

Thompson, T. (1962). Fashion Therapy. Journal of Home Economics, 54(10), 835-836.

Tomas-A. L., and Marron, SE. (2016). Body Image and Body Dysmorphic Concerns. Acta dermato venereological, 96 (217), 47.

Turner, T. (1993). “The Social Skin.” In: Reading the Social Body. Edited by C.B Burroughs and J. Ehrenreich. Iowa City: University of Iowa Press, 15-39.

Tiwari, G. K, and Kumar, S. (2015). Psychology and Body Image: A Review. Shodh Prerak, V (1), 1.

Venkatasamy, N., and Saravanan, D. (2015). Fashion Trends and its Impact on Society. India: Bannari Amman Institute of Technology: 1,8-9. 